\title{
Reviewing the Interactions Between Instructors and Students in Online Education
}

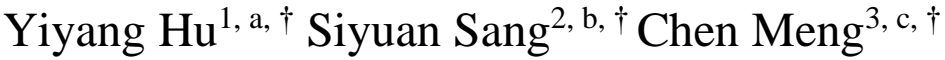 \\ ${ }^{1}$ Collge of Art and Science, Baylor University, Waco, Texas, 76706, United States \\ ${ }^{2}$ College of Foreign Language, Xinjiang University, Urumqi, The Xinjiang Uyghur Autonomous Region, 830000, \\ China \\ ${ }^{3}$ College of Foreign Language, Tongling University, Tongling, Anhui, 244000, China \\ *Corresponding author. Email: ${ }^{a} y i y a n g \_h u 1 @ b a y l o r . e d u,{ }^{b}$ siyuansang1230@163.com, ${ }^{c}$ mengchen0927@163.com \\ ${ }^{\dagger}$ These authors contributed equally.
}

\begin{abstract}
Online education has been increasingly frequently used in recent years, especially because of the influence that the Covid-19 had brought. However, the problem still exists since there are not enough interactions between teachers and students. In order to analyze the effects on online courses, our group adopts a qualitative, conversation analysis approach to explore the instructors' and students' interactive efforts to improve students' learning efficiency. To analyze its details, we reviewed some literatures about the interactions between teachers and students. Through this procession, it reveals that 1) synchrony as well as asynchrony modes have won increasing popularity among people as our society makes overwhelming progress; 2) teachers who have distinctive characteristics of flexibility, synchrony, and selfreflection play a dominant role in E-learning. 3) teachers are encouraged to be facilitators to guide students' learning by giving feedback or questioning during the class to help students. To sum up, interactions in online education settings will positively influence students' learnings, which should be encouraged and utilized in future classes.
\end{abstract}

Keywords: Online Education Development, Blended Learning, Online Interaction, Teachers and Students, Synchrony, Flexibility, Self-reflection

\section{INTRODUCTION}

This paper reviewed the topic of the online interactions between instructors and students, which is aimed at providing educators, instructors, and students with suggestions on online education. Interactions online did not gain enough attention in China until the recent decade, while Western scholars have considered relevant topics more and more important for years. From the review, we found that education development witnessed distinctions between the asynchronous and the synchronous educational modes. Teachers' roles are important in online education, especially teachers' characteristics, including flexibility, synchrony, and selfreflection. Also, teachers' roles as facilitators and their teaching strategies should be encouraged. We introduced this topic from three aspects: (1) Background information about online education; (2) The characteristics of teachers in online education; (3) Teachers and students' interactions in classes.

\section{BACKGROUND INFORMATION ABOUT ONLINE EDUCATION}

\subsection{Developing history of online education}

The developing process of online education could date back to the mid-19th century in England, evolved from correspondence courses. In the late 1970s, according to [1], there was a tendency for the "massification" of higher education. This might represent the beginning of online education. However, the current online education started in the 1990s with the advent of the Internet and the World Wide Web and continued to develop and became more sophisticated. Since then, online education has been widely used in organizations such as World Bank, United Nations Educational, Scientific and Cultural Organization (UNESCO), and so forth [2]. And the growth and development of online education technologies and methodology started after introducing the Web [3]. Currently, online education is still in its infancy, heading for its promising future. 


\subsection{Definitions of online education}

Online education is also called Web-based learning, online learning, and so forth [4]. It is an abbreviation of electronic learning, meaning any learning activity supported by information and communication technologies [5]. The use of computer network technology, primarily over an intranet or through the Internet, to deliver information and instruction to individuals can also be defined as online education [6]. Or to be simplified, learning and teaching online through network technologies [7]. Over the years, the basic content of online education has barely changed.

\subsection{Two modes of online education}

Delivered through different methods, online education can be divided into synchronous learning and asynchronous learning [8]. Synchronous learning needs both the teachers and the students to participate in online education activities simultaneously. In contrast, the asynchronous one allows the teachers to post the content in advance so that users can engage in web-based training at any time [3]. The network setup should allow for both synchronous and asynchronous exchange; students should have convenient access (e.g., through remote access); and the network should require minimal time for document exchange [9]. In short, both the applications that quickly respond to users and the fast network speed for teachers to upload electronic learning materials are of importance. As [10] point out, online education personalized instruction using digital content and innovative tools for instructional delivery. Both modes of online education are widely applied to educational institutions in these years. But there is a huge difference in the educational institutions they applied to. For asynchronous learning, it is used in traditional educational institutions such as high schools and even universities. A case in point, during the outbreak of COVID-19 when countries around the world had to adopt online education, professors and teachers in almost all the universities in China recommended an application called MOOC to students. MOOC uses recorded lecture to replace the offline courses and took the MOOC's participation into account of students' finals. While synchronous learning is widely used in after-school classes or hobby-oriented educational systems, their main foci are making profits rather than teaching students academically.

\subsection{Approaches to improve online education}

Scholars [11], [12], [13], [14] have tried to offer their own opinions on how to better online education since online education began to develop. [11] argue that the paradigm shift in teaching methodologies is necessary for meeting the challenges of the 21st-century curriculum, calling on educators to change their mindsets and embrace the technologies. To be specific, students need to know about information and communications technology (ICT). Otherwise, it will not increase participation rates, especially for individuals coming from undeveloped areas [12]. Although it is critical to developing the capacity strategy for online education as well [13], [14] raised a series of steps to refine the whole online education system, one of which is to provide faculty with development and support in project management, teamwork, evaluation, and time management. But this might be less efficient since providing all faculty with a set of training may cause a huge waste of valuable resources. If resources are distributed to limited but key members in the system, there is a probability of greatly improving efficiency.

\subsection{Online education's future and blended learning}

Optimism towards online education's future always prevails, resulting in predictions such as lifelong learning, m-learning, and so forth. [15] claim that blended learning will perhaps be a more significant growth area than fully online learning, meaning that blended learning will become the mainstream in the future. But such a trend is out of proof and constrained. On the one hand, blended learning is based on traditional teaching methods and new technologies. Once there is a bottleneck for either of these two, its development could be significantly blocked. On the other hand, [5] predicted a "better" development of online education than traditional training because of its potential to offer tailormade learning. Paradoxically, it can also create further barriers to learning, such as lack of hardware, fear of technology, and learner isolation. Obviously, online education is a powerful rival to traditional learning. And only a goal of mutual benefits or tremendous sacrifice could make two competitors cooperate and even merge with each other.

\section{THE CHARACTERISTICS OF TEACHERS IN ONLINE EDUCATION}

The characteristics of online education vary since online learning has become increasingly popular in recent years, especially during COVID-19. Therefore, we divide them into three parts.

\subsection{Flexibility}

Flexibility is one of the most distinctive traits of online education without the limitations of time and space. The discussion of flexibility through the understanding that flexibility is about, among other things, "the time, place and pace of learning and teaching", and as "a state of being in which learning and teaching are increasingly freed from the limitations of the time, place and pace of study", with this framing 
emphasized in 2018 editorial on openness [16]. Evidence indicates that effective use of these options can improve learning outcomes by stimulating students to engage more fully with their courses [17]. This argument is important to show the necessity of flexibility in class. Imagine that if something always abruptly happens that usually interferes when students devote themselves to studying, students' learning efficiency will be lower since they can't concentrate on the tasks. As the provision of flexible online learning becomes a pervasive practice and narrative, many universities and education providers tout flexibility, and invite learners to participate "on their schedule and on their terms" and claim that learners "can do it at night, they can do it in the morning around their work schedules, around their childcare" [16]. Thus, it is obvious that flexibility benefits students' learning.

\subsection{Asynchronous}

Asynchronous allows students to have quick feedback from their teachers through online classes. Asynchronous online-learning, commonly facilitated by media, including e-mail, videos, and other applications among learners and with teachers, even when students cannot be online at the same time. Students may spend more time refining their contributions, which are generally considered more thoughtful than synchronous communication [7]. However, suppose online-learners seldom meet face-to-face and teachers mainly rely on asynchronous e-learning. In that case, students might feel isolated and not part of learning communities, which is essential for collaboration and learning [7]. That is reasonable. For example, students are learning the grammar of past tense, and the teacher gives some examples of this grammar, such as "I went to the library yesterday." When students are required to make sentences like that, teachers can immediately give some feedbacks such as praising, and then students will be motivated to study harder. Therefore, their learning efficiency can be improved as well.

\subsection{Flexibility}

Compared to traditional classrooms, online-learning also has reflections, especially for teachers. Reflection refers to teachers' thinking about their practice both outside of the learning environment' reflection on action and during the teaching process 'reflection in action' [18]. As is known to all, there are various types of teaching contents, and the personalities of students differ from each other. Teachers can modify their teaching methods according to those things to make lessons more understood by students. Of course, when they take these things into consideration and make huge progress, they are experiencing self-reflection. In addition, since there are a large number of applications to use, teachers should check them in advance to make sure that something wrong will not happen during the class. Even during the class, they can use different methods in different software to improve classes to become active. In that case, the technology they use can be relatively proficient, which reflects online education. A number of instructional techniques can support reflection, such as weekly reports, concept maps, question prompts, teacher-led classroom discussions [19], or computer-supported collaborative learning environments [19]. In examining online teacher professional development (OTPD) studies, one sees the use of online technologies can support that teacher reflection no matter it related to online teaching or not. Meanwhile, vice versa, that online technologies can be used to support teachers' reflective practices which in turn could support teacher learning [20].

\section{TEACHERS AND STUDENTS INTERACTIONS IN CLASSES}

Teachers' role and behavior in class are some of the essential factors that affect students' learning. Teachers from different cultures have different roles to play. For example, according to [21], the teacher in Eastern countries' teachers tend to play the role of instructors. The role of a teacher is to construct a good teaching process. However, in Western countries, the role of the teacher is somewhat different. The teacher as a diagnostician and describes teachers' ability in students' thinking and problem-solving strategies. Moreover, the teachers are more likely to act as a mentor, facilitating classroom discourse. In classroom teaching, the role of the teacher is varied. Teachers could also be promoters and facilitate students' learning. The combination of the two roles can effectively promote students' performance in class.

\subsection{Questions in classes}

Questioning is one of the most common and effective strategies for promoting learning, whether online or in a face-to-face setting. Both online and offline teachers have similar roles in the same cultural background [22]. Teachers ask questions in two ways, close questions or open-ended questions. Open questions are designed to capture information that closed questions do not. A close question may be a knowledge question, which requires basic, limited, factual information, and the answer is mostly yes or no [23]. Closed question for example: "Do you like... ?" you answered "yes," "no," "don't know." [24] says, "Open questions don't have a definitive answer, while closed questions do." Teachers of openended questions can positively impact children's language use, especially vocabulary diversity and syntactic complexity (syntax) [25]. Open questions can promote the students' thinking when the teacher asks this kind of question, for example, how do you think? What do you think the next step we should take? Why this is an excellent way to solve problems. 
Open-ended questions teachers act as a facilitator role guiding and leading by the teacher's questions, promoting students to think further depth until they think to get the teacher's results. While [23] says that there is no better way to ask a question than the other, we should combine the two, such as' Can you tell me why?' If the students answer yes, in most cases, the students will continue to say what they think, while if the students say no, the teacher can either continue to use the open question, which step are you confound with? By combining the two types of questions, the teacher can quickly tell the student's mastery and where he or she is in doubt. We should keep the closed question's focus and particularity and keep the open question's richness and versatility.

\subsection{Feedback from both teachers and students}

In an online classroom environment, feedback from teachers and students can facilitate the adjustment of teaching methods that are more suitable for each other. Teaching feedback in many forms: written comments, verbal responses, and nonverbal gestures [26]. Teachers' timely response to student feedback is considered a necessary condition for effective learning. It enables students to "check and correct misunderstandings and get an immediate response to difficulties [27]." If the teacher does not answer the students' questions in time and does not know the students' knowledge loopholes, then the students' learning will be more difficult.

Nicol finds that the importance of feedback between teachers and students is similar no matter who is the receiver. Students in this study hope that teachers can help shape teaching by improving their effectiveness and acting on the feedback provided by students [27]. The role of students and teachers is mutual. When the teacher points out the problems of students, students can know their knowledge gaps. Students' feedback to teachers can improve the efficiency of the entire online course. It is generally accepted that effective feedback has a great impact on learning and student achievement. Students' feedback is one of the most influential factors in student achievements [28]. There is a lot of evidence that negative feedback is more effective than positive feedback. For example, a study finds that after receiving teacher feedback, the mean of students' self-focus score and the performance score is higher in positive feedback conditions than negative feedback conditions. Negative feedback can be more powerful in cultivating students' learning potentials than positive feedback [29]. Negative feedback, for example, "your answers are wrong;" "you do not have a good grasp of the skill." "you are not taking it seriously." Although this feedback may seem to undermine students' confidence, it can, to some extent, reflect students' problems, and they can self-reflect their problems and thereby improving themselves.
However, Low-level learners are more likely to react to negative feedback through experiencing negative emotions, show less motivation for subsequent tasks. For low-level students, they will regard teachers' negative feedback to discourage them. Hence, it will make them more reluctant to learn and fear to learn [30]. Therefore, positive feedback should be given to building students' confidence, self-awareness, and enthusiasm for learning. Positive feedback helps give students a sense of achievement and motivating them to make further progress. It can also positively reward them for strengthening their motivation and self-esteem during their studies [31]. For example, "you did a great job on this assignment;" "You made great progress on this test." When they get encouragement, they will think that their efforts have been noticed by the teacher, which gives them more confidence and external motivation to motivate them to continue learning.

\section{CONCLUSION}

In this article, we analyze the interactions between teachers and students in online teaching. We first found that with education development, asynchronous and synchronous education will undergo some distinctions due to the time gap, which might result in different students' learning outcomes. Furthermore, teachers play an essential role in online education, and their flexibility, synchronicity, and self-reflection are the main characteristics of teachers. Finally, teachers should play the role of mentors or facilitators in the classroom and adopt strategies such as questioning or feedback to promote teaching methods. Due to the outbreak of Covid19, we come to realize that online education is indispensable. It is challenging for teachers to achieve the efficiency and quality of traditional classroom, face-toface classes through online teaching. Generally, many teachers have not had a chance to getting in touch with online courses fully.

Moreover, online education characteristics are different. Hence, teachers need to adopt other teaching methods and pay close attention to classroom feedback and interactions between students. This article will help those who want to continue to teach online and students of online courses and who train teachers in institutions. It can help them to have a comprehensive understanding of e-learning as much as possible, which can help them become familiar with the mode of online education and thereby improving their teaching or learning efficiency. With the rapid development of the Internet, the convenience of online teaching will drive more students and teachers to select online learning. Therefore, online education will play an essential role in the future. Given that there is little research on online education, future research could focus on characteristics and different interaction types between teachers and students. 


\section{REFERENCES}

[1] Williams, J. B., \& Goldberg, M. (2005). The evolution of e-learning. Balance, fidelity, mobility: Maintaining the momentum, 725-728.

[2] Kumar, A., Kumar, P., Palvia, S. C. J., \& Verma, S. (2017). Online education worldwide: Current status and emerging trends.

[3] Bezovski, Z., \& Poorani, S. (2016, March). The evolution of e-learning and new trends. In Information and Knowledge Management (Vol. 6, No. 3, pp. 50-57). IISTE.

[4] Ruiz, J. G., Mintzer, M. J., \& Leipzig, R. M. (2006). The impact of e-learning in medical education. Academic medicine, 81(3), 207-212.

[5] Sambrook, S. (2003). E-learning in small organisations. Education+Training.

[6] Welsh, E. T., Wanberg, C. R., Brown, K. G., \& Simmering, M. J. (2003). E-learning: emerging uses, empirical results and future directions. international Journal of Training and Development, 7(4), 245-258.

[7] Hrastinski, S. (2008). Asynchronous and synchronous e-learning. Educause quarterly, 31(4), 51-55.

[8] Uden, L., Wangsa, I. T., \& Damiani, E. (2007, February). The future of E-learning: E-learning ecosystem. In 2007 Inaugural IEEE-IES Digital EcoSystems and Technologies Conference (pp. 113117). IEEE

[9] Volery, T., \& Lord, D. (2000). Critical success factors in online education. International journal of educational management.

[10] Powell, A., Watson, J., Staley, P., Patrick, S., Horn, M., Fetzer, L., ... \& Verma, S. (2015). Blending Learning: The Evolution of Online and Face-toFace Education from 2008-2015. Promising Practices in Blended and Online Learning Series. International association for K-12 online learning.

[11] Oriji, A., \& Amadi, R. (2016). E-education: Changing the mindsets of resistant and saboteur teachers. Journal of Education and Practice, 7(16), 122-126.

[12] Mashile, E. O., \& Pretorius, F. J. (2003). Challenges of online education in a developing country: research in higher education. South African Journal of Higher Education, 17(1), 132-139.

[13] Gunasekaran, A., McNeil, R. D., \& Shaul, D. (2002). E-learning: research and applications. Industrial and commercial training .
[14] Alexander, S. (2001). E-learning developments and experiences. Education + Training.

[15] Kim, K. J., \& Bonk, C. J. (2006). The future of online teaching and learning in higher education. Educause quarterly, 29(4), 22-30.

[16] Veletsianos, G., \& Houlden, S. (2019). An analysis of flexible learning and flexibility over the last 40 years of Distance Education. Distance Education, 40(4), 454-468.

[17] Daniel, J. (2016). Making sense of flexibility as a defining element of online learning. Athabasca University.

[18] Philipsen, B., Tondeur, J., McKenney, S., \& Zhu, C. (2019). Supporting teacher reflection during online professional development: a logic modelling approach. Technology, pedagogy and education, 28(2), 237-253.

[19] Lai, T. L., \& Land, S. M. (2009). Supporting reflection in online learning environments. Educational media and technology yearbook, 141154.

[20] Whipp, J. L. (2003). Scaffolding critical reflection in online discussions: Helping prospective teachers think deeply about field experiences in urban schools. Journal of teacher education, 54(4), 321333.

[21] Kaiser, G., \& Blömeke, S. (2013). Learning from the eastern and the Western debate: The case of mathematics teacher education. ZDM, 45(1), 7-19. doi:10.1007/s11858-013-0490-x

[22] Ertmer, P. A., Sadaf, A., \& Ertmer, D. J. (2011). Student-content interactions in online courses: The role of question prompts in facilitating higher-level engagement with course content. Journal of Computing in Higher Education, 23(2-3), 157-186. doi:10.1007/s12528-011-9047-6

[23] Worley, P. (2015). Open thinking, closed Questioning: Two kinds of open and closed question. Journal of Philosophy in Schools, 2(2). doi:10.21913/jps.v2i2.1269

[24] Cam, P (2006) Twenty thinking tools: Collaborative inquiry for the classroom. ACER Press, Camberwell, Victoria.

[25] Lee, Y., Kinzie, M. B., \& Whittaker, J. V. (2012). Impact of online support for teachers' open-ended questioning in pre-k science activities. Teaching and Teacher Education, 28(4), 568-577. doi:10.1016/j.tate.2012.01.002

[26] Plank, C., Dixon, H., \& Ward, G. (2014). Student voices about the Role Feedback plays in the 
enhancement of their learning. Australian Journal of Teacher Education, 39(9). doi:10.14221/ajte.2014v39n9.8

[27] Nicol, D. J., \& Macfarlane-Dick, D. (2006). Formative assessment and self-regulated learning: A model and seven principles of good feedback practice. Studies in Higher Education, 31(2), 199218.

[28] Gibbs, G., \& Simpson, C. (2004). Conditions under which assessment supports students' learning. Learning and teaching in higher education, 1(1), 331.

[29] Brunit, S., Huguet, P., \& Monteil, J.M. (2000). Performance feedback and self-focused attention in the classroom: When past and present interact. Social Psychology of Education, 3. 277-293.

[30] Kernis, M. H., Brockner, J., \& Frankel, B. S. (1989). Self-esteem and reactions to failure: The mediating role of overgeneralization. Journal of Personality and Social Psychology, 57(4), 707.

[31] Mathew, Binu \& Faculty, (2020). The role of feedback in classroom instruction. V. 7-11. 